\title{
The concentration of asbestos fibres during buildings exploitation analysis of concentration variability
}

\author{
Andrzej Obmiński ${ }^{1}$
}

Received: 7 January 2021 / Revised: 5 July 2021 / Accepted: 18 October 2021 / Published online: 8 November 2021

(c) The Author(s) 2021

\begin{abstract}
The goal of the research was to determine of average asbestos dust values in different types of buildings and possible deviations from these values, when taking measurements in different rooms of the same building. Variability of fibres concentration was analyzed over short periods of time in different places of tested building. The study included various types of buildings containing asbestos, typical for Central and Eastern European countries with different construction. An analysis was made of the reasons for the diversity of dust concentrations ranging from $<300$ to $16,000 \mathrm{fibres} / \mathrm{m}^{3}$ in connection with the building structure, asbestos location, degree of damage and intensity of building exploitation. Properly operated residential buildings containing asbestos inside outer sandwich walls features low concentration of dust $<300-400 \mathrm{f} / \mathrm{m}^{3}$. Novelty: Buildings not yet described by the literature were examined, as well as so-called emergency situations not related to the correct proceedings. This knowledge is necessary for the selection of technology in dismantling works and whether it is appropriate to remove asbestos from a given structure.
\end{abstract}

Keywords Asbestos $\cdot$ Respirable fibres $\cdot$ Concentration $\cdot$ Aerosol $\cdot$ Building exploitation $\cdot$ Buildings operation

\section{Abbreviations \\ ACM}

A-c panel

Asbestos structures

$\left[\mathrm{f} / \mathrm{m}^{3}\right]$
Asbestos-containing materials

Asbestos-cement panel, for example, PW3/A "asbestos structures"-fibres and fibre bundles with dimensions smaller than respirable fibres Fibres and bundles of asbestos fibres that do not meet the geometric criterion of respirable fibres

Czechoslovak Republic (Československá socialistická republika - ČSSR), was part of the Eastern Bloc Concentration of asbestos fibres in $1 \mathrm{~m}^{3}$ of the air

Andrzej Obmiński

a.obminski@itb.pl

1 Department of Thermal Physics, Acoustics and Environment at Building Research Institute, Building Research Institute (ITB), ul. Filtrowa 1, 00-611 Warsaw, Poland

\section{DDR (GDR)}

"Dynamic" method of samplin

NOAEL

$\mathrm{OM}$

PCM + PLM
(German Deutsche Demokratische Republik, colloquially East Germany) — a non-existent German state that was part of the Eastern Bloc

Implemented when the room is used for the operation and using of the room is imitated using fans and vibration of the environment for release of gravity settled dusts No-observed-adverse-effect levels

Optical microscope method Phase contrast microscope + polarised light microscope

SEM-EDS

Scanning electron microscopy with energy dispersion

TEM microscopy 
PEL

EM

Permission exposure level

Electron microscopy

\section{Introduction}

\subsection{Asbestos problem and the current question}

Most of the information regarding indoor asbestos dust concentrations was published over 10 years ago, and the reported data centres on American or Western European buildings. Since this pollution changes over the time, previously reported test results are no longer current. Specifically, the data do not apply to buildings in Central and Eastern Europe since the construction and used materials vary from those used in American or Western European buildings. The recorded values of asbestos dust concentrations in a room are often more dependent on the characteristics of the room than on the type and condition of asbestos-containing products. An example is provided in Fig. 1 and described in detail in Sect. 1.3.

Many large buildings with durable construction, significant value, and anticipated long life contain ACM in sandwich panel walls or facades are still in use today. This is illustrated in Fig. 2 and described in Sect. 2.2, along with Fig. 3a, which is described in Sect. 3. These buildings include hospitals, office buildings, factories, etc. that are currently occupied and will continue to be used due to the inability to replace them with other asbestos-free buildings. Many of these buildings, such as apartment blocks in estates, have been thermally insulated recently without asbestos removal. The a-c panels, contained in the facade, were covered with mineral wool or foamed polystyrene. Subsequently, a modern facade was added. The process of coating of old buildings a new thermal insulation in Europe and other countries was bound by energy saving recommendations. This process gained momentum in the last few years overlapping with the effect of the widespread use of asbestos facades and walls in the past. There is now public pressure to remove asbestos from all buildings over the next 12 years.

On the other hand, it is difficult to decide whether to remove asbestos, including building demolition, or covering walls with a new facade. Asbestos-containing materials are often not visible with unknown technical condition. We do not know the real and current concentrations of asbestos dust in buildings and the dust hazard can be extremely low. Examples of building pollution and differences in the results obtained from the literature data and current research are presented below. The differences in the presented values result from differences in the facilities, applied research methods, analytical sensitivity, size of counted fibres, scale of damage and type of ACM or activity of users in the building. In 200 buildings and 1400 samples from them, analysed using the TEM technique, the average value of pollution was $270 \mathrm{f} / \mathrm{m}^{3}$ [1]. The highest contamination occurred in the school $\left(500 \mathrm{f} / \mathrm{m}^{3}\right)$. The sources (of 9 researchers) quoted by this report [1] within the same building category differ slightly with regard to "respirable fibres", e.g. in the analysis of school buildings (from 300 to $420 \mathrm{f} / \mathrm{m}^{3}$ on average). The results from these buildings vary considerably in terms of the amount of so-called "asbestos structures" (from 2000 to $58,000 \mathrm{~s} / \mathrm{m}^{3}$ ). Mechanical release of fibres from products (primary—of disturbance and/or secondary fibres releaseof indoor activity) results in a dramatic increase in the concentration of asbestos in the air. It also depends on the place of work e.g.: repairing a ceiling is the effect of $45,000 \mathrm{f} /$ $\mathrm{m}^{3}$, repairing a roof increases the concentration from 100 to $120,000 \mathrm{f} / \mathrm{m}^{3}$. Asbestos disassembly, as external disturbance, can generate asbestos concentration levels even above $1,000,000 \mathrm{f} / \mathrm{m}^{3}$ in the surrounding work area, which exceeds the operational pollution of damaged products by over 5000 $\times[2]$. As a result, the removal process may pose a long-term risk impact on the environment, building, and its users. This is not a rare phenomenon. However, it is rarely detected and may pose a risk of long-term effects of increased pollution on the environment of the building and its users.

Should the decision on widespread removal of asbestos in buildings such as apartment blocks or hospitals be obligatory, assuming the process can be safely implemented and that these buildings will be continued to be used throughout the process? Would disassembly be better in all cases compared with proper use of these buildings until the end of their live cycle without disturbing the asbestos? To answer these questions, both literature and experimental data were collected to compare the results of many years of asbestos research in these buildings. The purpose of this work was to determine the average values of asbestos dust concentration in various types of buildings. In addition, the range of fluctuations of these values in short-term tests has been specified. To understand the results, the differences in the recorded concentration of dust in different rooms of the same building at the same time must be carefully considered.

\subsection{Literature review in terms of risk assessment, diversity of procedures and research results of buildings contamination}

The data and opinions presented in the literature regarding asbestos are highly dependent on different techniques and the subject of research. The differences in dust concentrations from similar facilities can be very large. This applies to all measurements. In the surrounding air, the concentration range of fibres coming from the corrosion or destruction of building materials is in the range of $<200-2400 \mathrm{f} /$ $\mathrm{m}^{3}$ and depends on the external conditions, distance from sources, degree of corrosion, etc. This results in an average 
Fig. 1 Examples of various dust sources that can cause low asbestos pollution if embedded dust is not activated. Despite the poor technical condition of the asbestos, the pollution of the unused room does not exceed $0.3-0.5 \mathrm{f} / \mathrm{L}\left(300-500 \mathrm{f} / \mathrm{m}^{3}\right)$

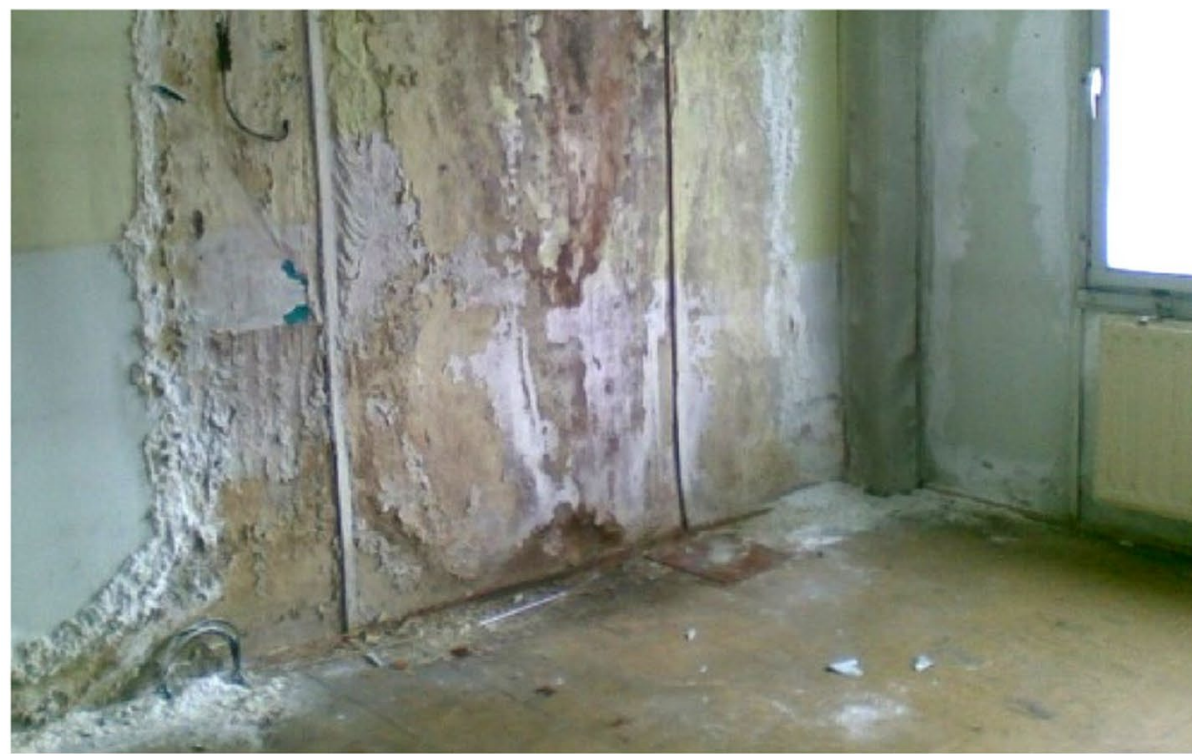

(a)
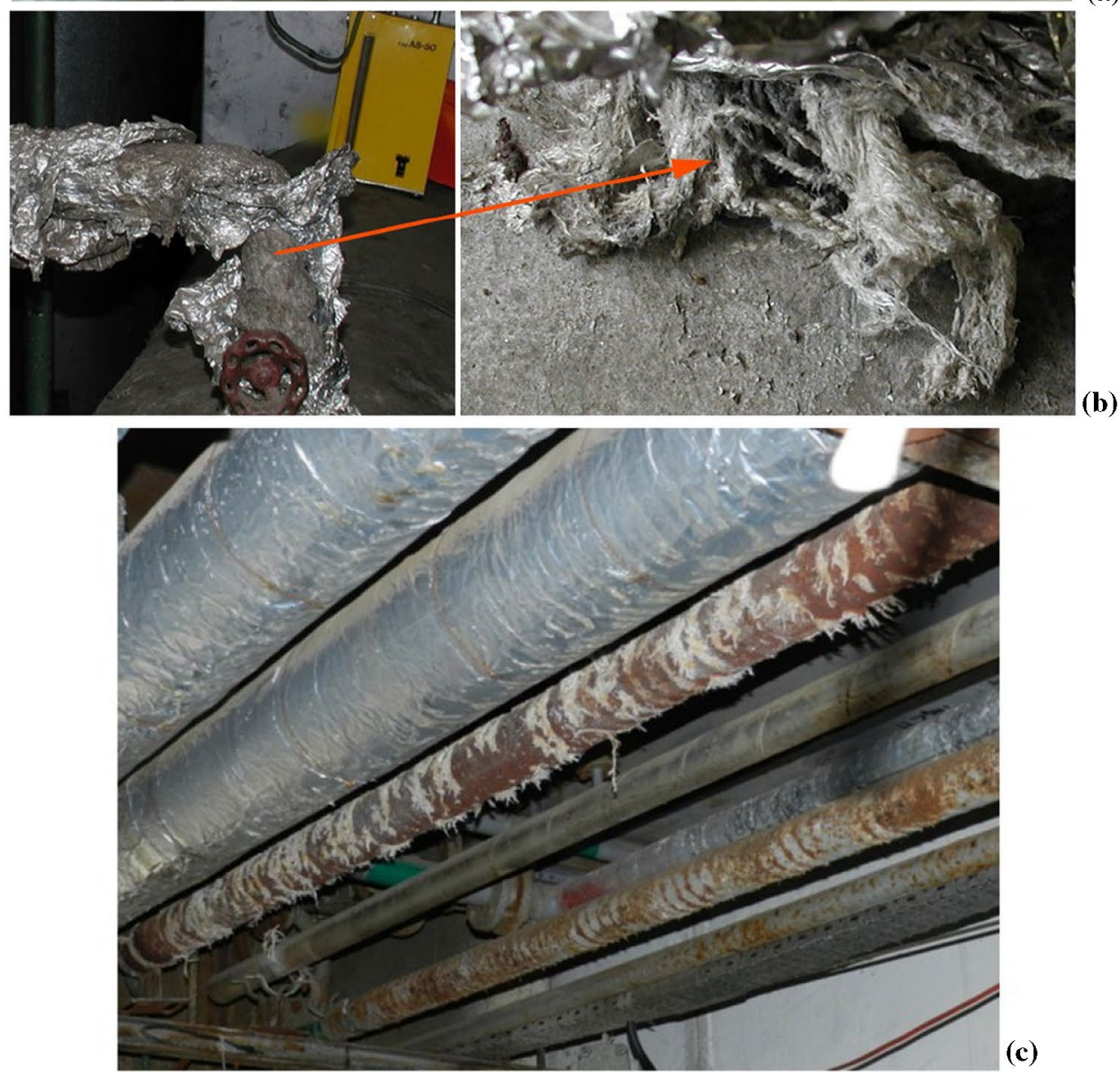

concentration of $100 \mathrm{f} / \mathrm{m}^{3}$ in cities and in the rural $10 \mathrm{f} / \mathrm{m}^{3}$. The report [3] quotes Lee and Van Orden (2007). Measurements of 1600 samples by TEM for outdoor air in the range $10-1000 \mathrm{f} / \mathrm{m}^{3}$ and for indoor air up to $50-200 \mathrm{f} /$ $\mathrm{m}^{3}$. In the years 2004-2008, outdoor air in Poland was characterised by significant differences between regions depending on the amount of a-c products used in construction. Mostly the values up to $400 \mathrm{f} / \mathrm{m}^{3}$ were interpreted as "low concentration" with a frequency of about $20 \%$ [4]. Above this value, there are three more concentration levels with a total share of $70-80 \%$ of the results. For further 

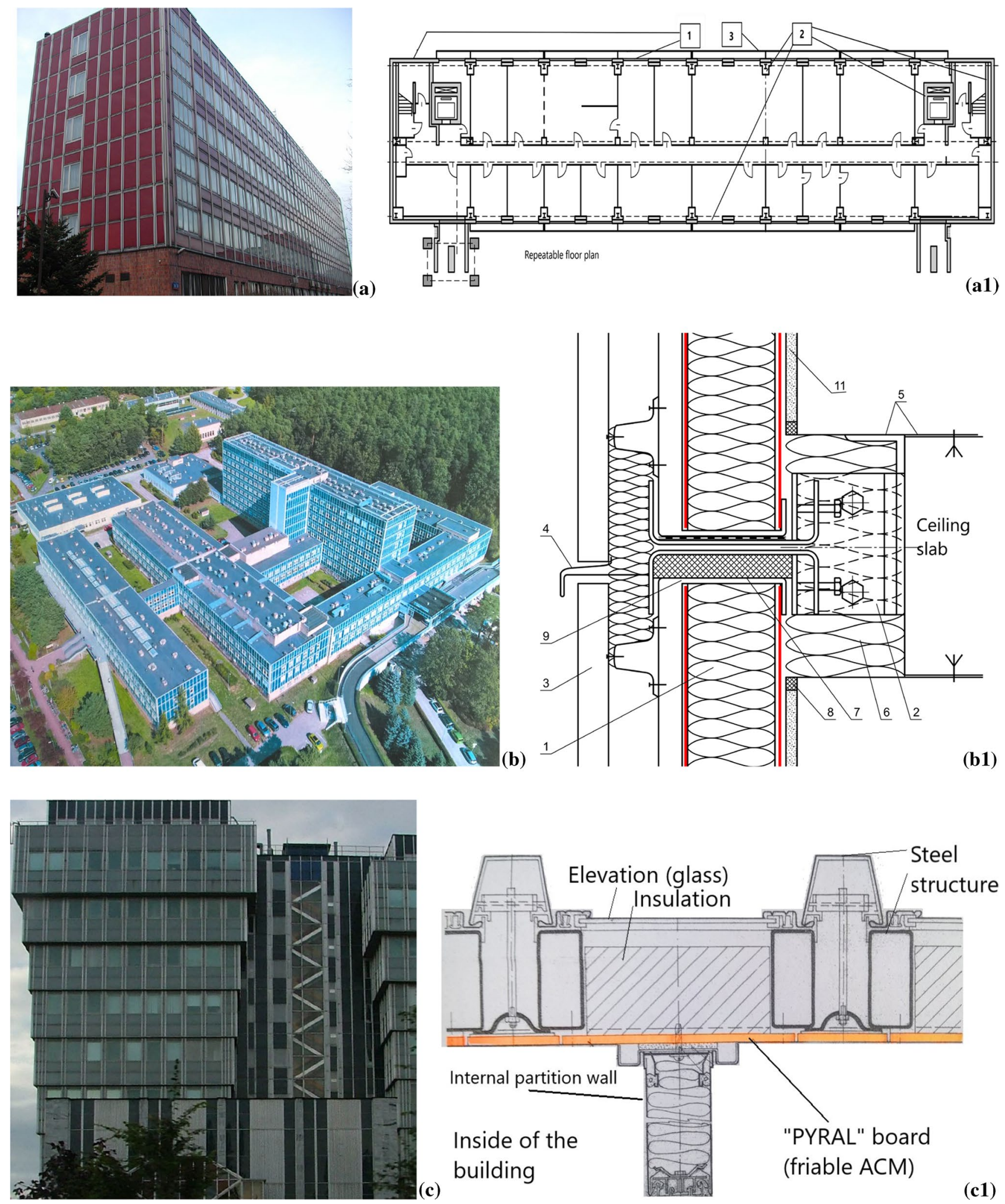
४Fig. 2 Building systems types "LIPSK", "BISTYP" and "BOLETICE". a LIPSK system building, five-storey building with a coloured glass facade. Typical appearance of light steel "non-rigid" structure with 70 s external sandwich wall with ACM. Usage: general construction, schools, offices, hotels, dormitories, health centres. a1 The part of the repeated floor plan of the "LIPSK". On the external side of the sandwich wall (1), an asbestos-cement boards called "GLAGIT" ware mounted. On the outside, the sandwich wall is covered with a facade made of coloured glass or aluminium sheet (3). Soft boards, containing "friable" asbestos- "SOKALIT" ware marked with the no. 2 (the inner side of the sandwich wall, fire-resistant lining of the steel structure columns, the cladding of the elevator shaft and staircase constituting an escape route). b Typical hospital complexes in the "BISTYP" system. Typical layout of provincial hospital buildings in a number of Polish cities. b1 Vertical section through outer sandwich wall with a PW3/A board in "BISTYP-3" system. Markings: 1-PW3/A insulation board (red marked asbestos-cement boards protecting the mineral wool core), 2-fasteners, 3-coated corrugated sheet, 4-flashing, 5-reinforced contact plate, 6-mineral wool from the side of the ceiling slab , 7, 8-gaskets, 9, 10-joining profiles (steel), 11-dry plaster boards. c System "BOLETICE", view of the front wall. This system was a design of the former CSRS: nonrigid steel construction containing layered walls with "friable" ACM ("PYRAL"). c1 The layered wall in cross section. A curtain wall layer contained an elevation layers (made of tempered glass embedded in an aluminium frame), air gap, mineral wool, layered plate containing "friable" ACM, about 25\% of chrysotile asbestos (plate called "PYRAL"), covered with aluminium foil. From the inside: GK boards (a cardboard-gypsum board). The location of the "PYRAL" layers in the sandwich wall is marked in orange

comparison [5], significantly lower values of $10 \mathrm{f} / \mathrm{m}^{3}$ were confirmed by TEM in the ambient air (rural).

The interior of buildings undergoing renovation or removal of asbestos-containing products with various concentrations ranging from 100,000 to $600,000 \mathrm{f} / \mathrm{m}^{3}$. For similar conditions and methodology, other authors obtained values of $2100-56,000 \mathrm{f} / \mathrm{m}^{3}$. Destruction of weathered products may increase the concentration by more than 300,000 times [3]. Large differences in results obtained using similar methods (i.e. PCM + TEM) have been reported for internal air testing of schools with heating asbestos-containing installations, e.g. $50 \mathrm{f} / \mathrm{m}^{3}$ on average. A maximum concentration measured of $4300 \mathrm{f} / \mathrm{m}^{3}$. PCOM analysis results were below LOQ (statistically relevant limits of quantification) [6]. This was confirmed by a report regarding similar objects where the asbestos dust concentration in indoor air exceeded ambient air conditions by $4-5$ times. At the same time, extremely low concentrations of $50-100 \mathrm{f} / \mathrm{m}^{3}$ were registered in similar schools for another TEM study.

The dust concentrations obtained by passive static sampling technique (unconventional method using electrostatic charge) during disturbed (ACM) showed the dependence of the concentration on the type of asbestos. The concentration depended on kind of asbestos fibre: Chrysotile fibres concentration of $9000 \mathrm{f} / \mathrm{m}^{3}$ corresponded to the amphibole concentration of $49,000 \mathrm{f} / \mathrm{m}^{3}$ [7]. Outdoor air tests using $\mathrm{PCM}+\mathrm{SEM}$ techniques showed significant differences in values with in the same city (in Iran) with an average of $1200 \mathrm{f} / \mathrm{m}^{3}$ max and 18,000 f/m $\mathrm{m}^{3}$ [8]. The concentration of asbestos fibres measured in the urban air using PCOM was average 12-fold lower than the results obtained with the SEM technique [8]. PCOM study of occupational exposure in short-term and annual occupational exposure measurements in roofing removal confirmed result well below chrysotile (NOAELs) for asbestos-related diseases [9]. However, the average exposure for workers depends on many factors, including those not only related to ACM products, such as working conditions and also the type of work. Average worker exposure was determined during renovation and demolition of old buildings covered with a-c. The result was in the range of $300,000-600,000 \mathrm{f} / \mathrm{m}^{3}$ for roofs and about $100,000 \mathrm{f} / \mathrm{m}^{3}$ for facades [10]. Other studies in simulations of roofers' exposure during various processing activities of ACM products measured by PCOM techniques obtained a concentration range of $5000-32,000 \mathrm{f} / \mathrm{m}^{3}$ and a simultaneous TEM result of $2100-56,000 \mathrm{f} / \mathrm{m}^{3}$ [11].

This is applicable to the air in work zones ("area tests"), "personal samples" from employees, and indoor air throughout an entire building. There are also reports on a low level of occupational exposure (in relation to PEL) for roofing projects with ACM roofs $[8,12]$ which was in the range of $4700-75,200 \mathrm{f} / \mathrm{m}^{3}$ and in work zones at $600-16,000 \mathrm{f} / \mathrm{m}^{3}$. Low levels of building exploitation may result in exposure values during use. A study of 49 buildings with and without ACM products showed no statistically significant differences between outdoor and indoor air and no differences between buildings. The average concentration of respirable fibres measured by TEM was $70-120 \mathrm{f} / \mathrm{m}^{3}[12,13]$. Low asbestos concentrations (average $20,000 \mathrm{~s} / \mathrm{m}^{3}$ and $70 \mathrm{f} / \mathrm{m}^{3}$ - for respirable fibres) were also confirmed in the 315 buildings in use, regardless of the technical condition of the ACM significantly below the adopted PEL for Occupational Safety standard $(0.1 \mathrm{f} / \mathrm{ccm})$ [14]. On the other hand, depending on the condition of asbestos products subject to destruction, there is also the possibility of high asbestos dust concentration. During damaged roof slates asbestos fibre concentration measured by SEM and PCOM was on the range approx. $50,000-388,000 \mathrm{f} / \mathrm{m}^{3}[15]$ and even 300,000-600,000 f/m [10].

Different concentrations apply to fibres with different fibre sizes, e.g. the number of "asbestos structures" (fibres or fibre bundles below the respirable size) $17,000 \mathrm{f} / \mathrm{m}^{3}$ inside individual building corresponded with the number of respirable fibres ( $>5$ um long) attributing to only $230 \mathrm{f} / \mathrm{m}^{3}$ [16]. Dust concentration is also dependent on the activity performed in the studied area. As evident in short-term measurements using a laser meter the measured differences varied from that reason from 2500 to $60,000 \mathrm{f} / \mathrm{m}^{3}$ [17]. Using TEM to measure maximum and minimum asbestos dust concentrations, the values differed by a factor of 10 compared with 

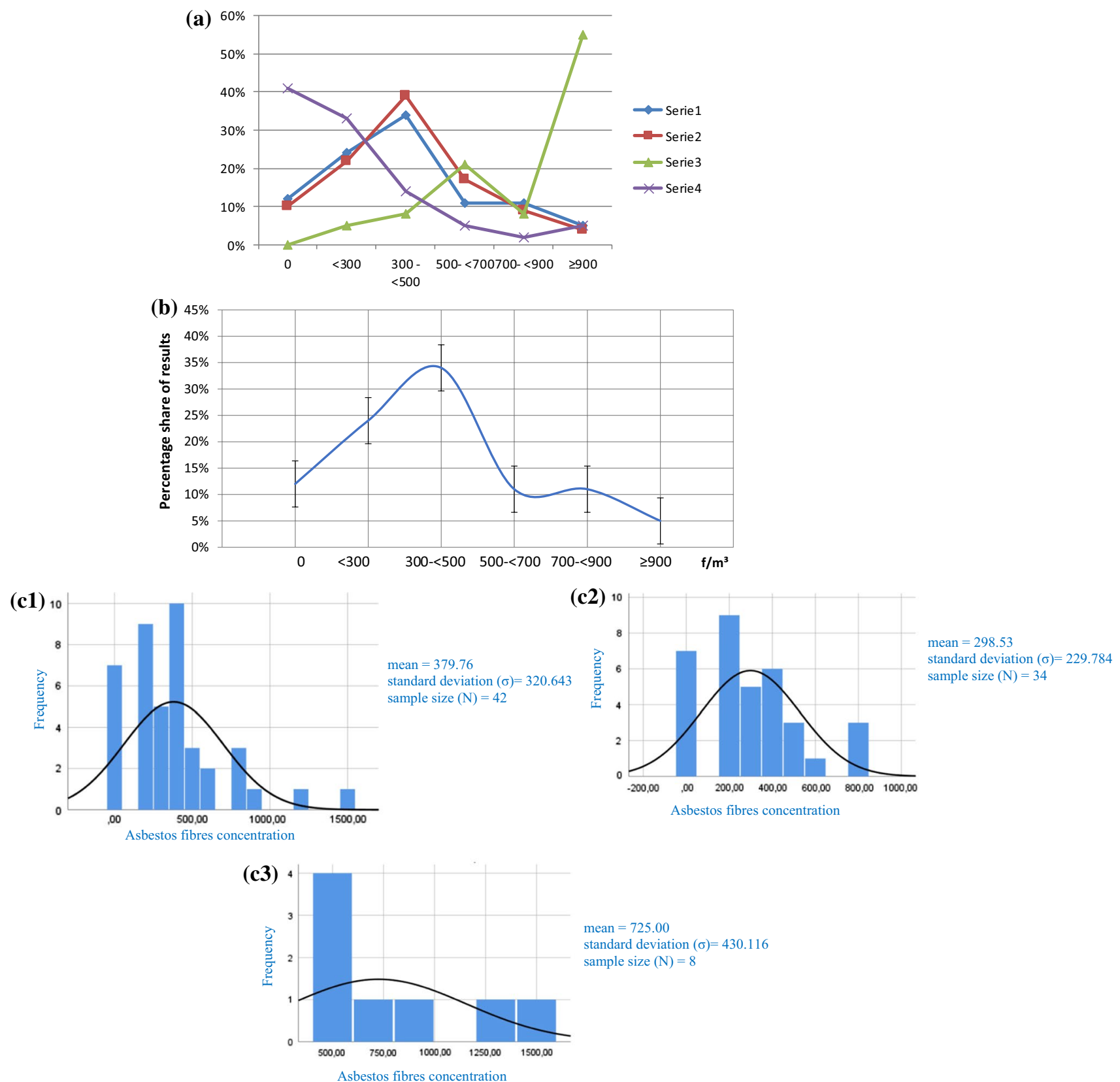

Fig. 3 a Distribution of contamination indoor air recorded in buildings type "LIPSK", with the simultaneous free flow of air between the rooms. b The most common percentage share of results in a typical buildings "LIPSK" (building type 1-2). $\mathbf{c}_{1}$ The distribution of asbestos fibres concentration of in measured rooms of the "LIPSK"

the average concentration of $1500 \mathrm{f} / \mathrm{m}^{3}$ [18]. The concentration values are, therefore, highly dependent on the "intensity of use", i.e. how the building is used. Conversely, the lack of correlation of concentration with many factors, including exploitation, was presented using the TEM technique [16]. In the opposite, the other authors confirm this effect on asbestos concentrations in the air $[14,17,18]$. The surplus of asbestos dust in the indoor air in relation to the building building No. 1. $\mathbf{c}_{2}$ The distribution of asbestos fibres concentration of in "a" rooms of the "LIPSK" building No. 1. $\mathbf{c}_{3}$ The distribution of asbestos fibres concentration of in "b" rooms of the "LIPSK" building No. 1

surroundings was confirmed [17]. The results for similar rooms tested in a specific one building may vary by several thousand $\mathrm{f} / \mathrm{m}^{3}$ but could exceed the value of $100,000 \mathrm{f} / \mathrm{m}^{3}$ when analysed by electron microscopy (up to a maximum of $200 \times 10^{6} \mathrm{f} / \mathrm{m}^{3}$ in the case of improper work) $[19,20]$. Examples are presented in Table 1. According to the analysis of the above reports, a very large differentiation of asbestos concentrations fibres in the air for similar buildings with 
Table 1 Asbestos fibre concentration during selected examples of work

\begin{tabular}{|c|c|c|}
\hline Type of activity performed & $\begin{array}{l}\text { Surrounding in the work area; } \\
\text { Concentration }\left[\mathrm{f} / \mathrm{cm}^{3}\right]\end{array}$ & $\begin{array}{l}\text { Worker exposure (distance about } 30 \mathrm{~cm} \\
\text { from the cassette with individual air } \\
\text { sampler) } \\
\text { Concentration }\left[\mathrm{f} / \mathrm{cm}^{3}\right]\end{array}$ \\
\hline Drilling asbestos plaster (friable ACM) & 0.59 & 0.78 \\
\hline Disassembly of the heating furnace (friable ACM) & 0.12 & 4.7 \\
\hline $\begin{array}{l}\text { Cutting a-c panels using a specialised saw with dust extraction } \\
\text { (non-friable ACM) }\end{array}$ & 0.07 & $0.008-0.44$ \\
\hline Drilling in a-c plates (non-friable ACM) & - & $0.42-0.75$ \\
\hline Work with insulating cords and asbestos bands & 0.19 & 0.34 \\
\hline Repair works of brakes in motor vehicles & - & $3-7$ \\
\hline $\begin{array}{l}\text { Dust emissions from the clothing of a worker cutting an asbestos- } \\
\text { cement pipe }\end{array}$ & $0.52 *$ & \\
\hline
\end{tabular}

TEM recorded. Example values based on report compilation [19, 20]

*The mean phase contrast microscopy equivalent (PCME) in accordance with NIOSH methods 7400 and 7402 [19]

similar requirements is shown. This is due to a number of factors related to the features and nature of asbestos-based products. Other factors unrelated to the products themselves or even to the structure of the tested buildings can have just as large of an impact on asbestos exposure. These may be factors that are not visible or not registered by those examining the building, e.g. ventilation of the room by users in the period preceding the sampling or ACM damage invisible in the room. This fact makes it impossible in practice to make accurate comparisons of concentrations recorded by different researchers, emphasising the range of variability in these concentrations.

In contrast to demolition, the widespread operating values in the buildings in use ranged from 20 to $2400 \mathrm{f} / \mathrm{m}^{3}$, with an average concentration of $20-500 \mathrm{f} / \mathrm{m}^{3}$ [1]. New studies from Asian regions $[15,21]$ present pollution values in renovated buildings (on level $3800 \pm 1100 \mathrm{f} / \mathrm{m}^{3} \mathrm{f} / \mathrm{cm}^{3}$ ) similar to those reported for the building type "BERLIN" in Poland. Very large variations in dust concentrations in residential buildings (from 0 to $1,000,000 \mathrm{f} / \mathrm{m}^{3}$ ) [2] are associated with variable factors, e.g., product condition, type of asbestos products, and external air pollution. When measuring external pollutants in non-industrial areas, the range of $0-1000 \mathrm{f} / \mathrm{m}^{3}$ was exceeded in some regions (Poland) [22]. The distribution of values within indoor building air is particularly marked [2], as confirmed by the author's research in renovated buildings and buildings following renovations. Samples from an individual collection of workers removing asbestos indicates higher values than those collected in the removal area. Personal samples containing concentration range of 56,000-550,000 f/m $/ \mathrm{m}^{3}$ from asbestos removing workers corresponded on average to the values of "area" tests with concentration $16,000-23,000 \mathrm{f} / \mathrm{m}^{3}[22,23]$. The variability of recorded dust concentration is also impacted by the elapsed time from the formation of the aerosol to the measurement $[24,25]$. In the period of normal operation within 6 years, the indoor concentration of fibres can be self-reduced even 26 times (due to gravity, sedimentation, air exchange in building, etc.) $[24,25]$.

\subsection{Examples of pollutant values in various situations recorded in the research}

In some rooms (depending on circumstances), dust concentrations in one building can change from $<1000$ to $7000 \mathrm{f} / \mathrm{m}^{3}$ [24]. For "LIPSK" buildings, discussed later in this article, the objects in good condition and prior to asbestos removal were in the range of contamination $300-600 \mathrm{f} / \mathrm{m}^{3}$. The same objects immediately after the removal of ACM products were contaminated in range $7000-25000 \mathrm{f} / \mathrm{m}^{3}$ and after 10 years from the end of the removal of $300-800 \mathrm{f} / \mathrm{m}^{3}$ [25]. The difference in results depends on many factors, including: possibility of dust transport in the building, user activity within the tested facility, air humidity, the degree of air exchange (before and during the collection of test sample), the distance of the sample collection from the source of dust emission, "dynamic" or "static" sampling, etc. Such variation in concentration value undermines the desirability of extremely accurate and expensive measurements by methods with a high sensitivity of $10 \mathrm{f} / \mathrm{m}^{3}$. In "LIPSK" and "BERLIN" buildings, the average operational damage of asbestos products is most commonly reported by asbestos dust concentration values in the range of $<300-500$ (max of $800 \mathrm{f}$ / $\left.\mathrm{m}^{3}\right)[26,27]$. In used "LIPSK" buildings, with good technical condition and protected ACM products, with an average concentration of asbestos dust $<300 \mathrm{f} / \mathrm{m}^{3}$, the concentration range in various rooms may vary in short-term single measurements in the range of $0-1800 \mathrm{f} / \mathrm{m}^{3}$ [27]. Another example of variability of pollution in the same building, measured in the same time (during the asbestos removal): 
outside the hermetic zone of disassembly works in the range of $600-2500 \mathrm{f} / \mathrm{m}^{3}$, and with "area zone" contamination, in the closed disassembly zone $23,500 \mathrm{f} / \mathrm{m}^{3}$ [27]. The disassembly of non-asbestos elements in this building increases asbestos dust concentrations in internal air within a range of $2000-5000 \mathrm{f} / \mathrm{m}^{3}$ [27]. It is assumed that the elevated level of asbestos fibres in the air of used buildings is combined with the degree of damage to asbestos products and possibility of formation of aerosols [28]. This has been confirmed in reports $[29,30]$. A similar conclusion follows from the publication of 1986-2009 by G. J. Burdett. However, damage to the product is not sufficient for aerosol formation. For example, for completely degraded products under natural air humidity (70\%), the absence of object operation, and lack of dynamic sampling, the values asbestos fibres in the air was reported to be below $500 \mathrm{f} / \mathrm{m}^{3}$. Theoretically (Fig. 1c), these concentration values should be significantly higher.

Introduced markings:

(a) "BERLIN"- type building with a decaying SOKALIT (friable asbestos) board inside. The reason for the destruction is the freezing of walls and their dampness (indirect poor thermal insulation of the external wall).

(b) Cords from chrysotile asbestos. Photographs of neighbouring products in a heat and power plant, excluded from use. The pipeline of hot steam shown on photo. In the background, yellow aspirator collecting the air sample for testing asbestos fibres concentration

(c) Remnants of asbestos cords after their incorrect removal from an industrial facility.

The differentiation of the test results was confirmed depending on the types of ACM products. Greater differentiation was confirmed in the results of the so-called area samples than in the asbestos removers collected in individual dust meters [31]. Large differences in the studied areas result from the differences in the distance between the place of collected samples and the dust source. The differentiation of the concentration resulting from (mechanical) disturbances is recorded especially in the so-called "area" samples [32].

\section{Methods of analysis}

\subsection{Microscopy methods}

\subsubsection{Sampling}

The author took all air samples himself. An AS-50 dust meter and an independent rotameter with a reading accuracy of 0.1 $\mathrm{L} / \mathrm{min}$ were used. Samples were generally taken in buildings during their operation, mostly using the "dynamic" method according to the sampling standard [33]. In each building, samples were collected on all floors (to take into account the average of cubature of the indoor air). Several rooms were randomly selected on each floor and two samples were taken. The averaged values from these two results were treated as a single averaged result of the dust concentration in a single room. When examining the population of results with the Shapiro-Wilk test of the samples (Table 5), the values were not averaged. Research methodology used is presented in Table 2.

\subsubsection{Microscopic analysis}

The purpose of using microscopy-based analytical methods was a modified test of OM (PCM + PLM). The method allows for determination of asbestos fibre concentrations contained in indoor air [27]. The results were verified in parallel using SEM-EDS and TEM tests. Tests using the SEM-EDS microscope were performed in Germany, in an accredited laboratory (WESSLING) according to the standard [34]. TEM tests were performed in France, in an accredited laboratory (EUROFINS) according to the [35].

The analysis (OM) used phase contrast (PCM) [27, 36], which easily registers high concentrations of asbestos respirable fibres and is commonly used for conditions of strong asbestos aerosol dominance in the air, which occurs during

Table 2 Research methodology used

\begin{tabular}{|c|c|c|c|}
\hline \multirow[t]{2}{*}{ Laboratory } & \multirow[t]{2}{*}{$\begin{array}{l}\text { Author research: sampling and analysis } \\
\text { ITB (Poland) }\end{array}$} & \multicolumn{2}{|c|}{$\begin{array}{l}\text { Author's sampling, selected sample } \\
\text { analysed by }\end{array}$} \\
\hline & & Wessling (Germany) & Eurofins (France) \\
\hline Research method & $\begin{array}{l}\text { OM: (PCM+ PLM) } \\
\text { PCM (fibre counting) } \\
\text { PLM (asbestos identification) }\end{array}$ & SEM-EDS & TEM \\
\hline Air flow through the filter [L/min.] & 15 & 15 & 7 \\
\hline Flow time $[h]$ & $1.5-2$ & 23 & 24 \\
\hline Magnification $[x]$ & $500-1000$ & 2000 & $2000-5000$ \\
\hline The limit of quantification $\left[\mathrm{f} / \mathrm{m}^{3}\right]$ & $\geq 300$ & 170 & 100 \\
\hline
\end{tabular}


asbestos removal from a building. This method is only suitable for quantitative analysis (fibre counting) [37], not for fibre identification. However, this method is indicated for use in the assessment of exposure by comparing historical research and contemporary results [38].

To test the concentration of asbestos fibres in buildings where asbestos fibre concentrations can range from $<300$ to $>10,000 \mathrm{f} / \mathrm{m}^{3}$, optical microscopy using phase contrast including light polarisation (PCM+ PLM) was performed. This technique can easily record pollution values above 300 $\mathrm{f} / \mathrm{m}^{3}$, thus excluding or affirming high asbestos dust concentrations between 300 and $1000 \mathrm{f} / \mathrm{m}^{3}$. Measurements to count asbestos respirable fibres concentration were made using a PCOM method of optical phase contrast microscopy (analogous to 7400 NIOSH] and the Polish standard PN88/Z-04202/02 [39]).

Simultaneous identification of asbestos fibres was carried out in polarised light with the assessment of morphology and optical properties of fibres $\emptyset>0.1 \mu \mathrm{m}$. Observations were carried out at a magnification of $500 \times$ or $1000 \times+$ immersion (if necessary). The modification of techniques [25, 30] in relation to the requirements of the 7400 NIOSH standard consisted of:

- Increasing filter air flow in relation to the standard requirements of 10-12 L/min with the assumed volume of air passed through the filter of approximately $1.5-2 \mathrm{~m}^{3}$ (more if necessary);

- Increasing the number of observation fields on the filter (recorded within the Wallton-Becket grid) in relation to standard requirements from 100 to 400 (more if needed);

- The identification of each of the counted fibres as asbestos respirable fibres was based on the optical asbestos characteristics.

The expanded uncertainty, depending on the number of counted fibres and the number of observations made for the tested filter ranged from 15 to $40 \%$ of the result. Most often, for concentration values of $400-900 \mathrm{f} / \mathrm{m}^{3}$ and 400 observations of each filter, it was about $22 \%$.

\subsection{Tested buildings}

The examined buildings were in constant use since their construction approximately 30 years ago. Below examples of tested systems (Fig. 2).

The buildings were manufactured in the countries of the former "Eastern Bloc" and currently used (or removed) in the Czech Republic, Slovakia, eastern lands of Germany (DDR), Poland. The subject of the research were buildings of so-called "rigid" and "non-rigid" construction. Table 3 presents examples of them.
First, buildings with brick walls were inspected, followed by buildings of lightweight structures with layered walls. These had steel or wooden frames with applied products containing asbestos from the "friable" and "nonfriable" groups inside and outside.

Products with asbestos were analysed in terms of their location in the building:

(a) Inside the object were asbestos-cement, cladding of sandwich panels with a heat-insulating core made of mineral wool, and/or "friable" products with a high percentage of asbestos (usually little above $20 \%$ ). With a relatively small proportion of binder, these products are subject to easy mechanical destruction, causing high dusting. These mainly consisted of insulation boards, a product known as "SOKALIT" in building types "LIPSK" and "BERLIN". These buildings were manufactured until the 1980s in DDR. Another example of a similar construction is the "BOLETICE" system which is based on CSRS products from the $90 \mathrm{~s}$;

(b) External products were facades of buildings made of asbestos-cement panels ("non-friable", usually 5-13\% asbestos). These were building solutions widespread throughout Europe;

(c) "S" - System "BISTYP"-1 or 2. These buildings possess a skeletal structure (non-rigid steel, similar to "LIPSK"), without the use of asbestos friable products covering steel constructions. System "BISTYP" contains PW3/A: a heat-insulating core made of mineral wool, covered on both sides with a pressed asbestoscement plate (a-c). Asbestos in this building is found only in the form of an element of the inner sandwich wall consisting of the PW3/A package. This package from the outside is covered with tempered glass or corrugated steel sheet, or other elevation. From the inside it is covered with a cardboard-gypsum board (GK);

(d) "B"-Buildings with a skeletal structure (without the use of asbestos friable products covering steel constructions, similar to "S") containing asbestos-cement plates inside a curtain wall layer of the PW3/A or PŻW3/A package. From the inside of rooms are GK boards. From the outside, buildings are covered with an insulating layer of polystyrene or mineral wool and covered with plaster facade. "S" and "B" are buildings produced until the $90 \mathrm{~s}$ in Poland with similar construction.

\section{Results and discussion}

\subsection{Cases building type "LIPSK"}

The assessment of the variability in results regarding asbestos dust concentrations for individual buildings is presented 


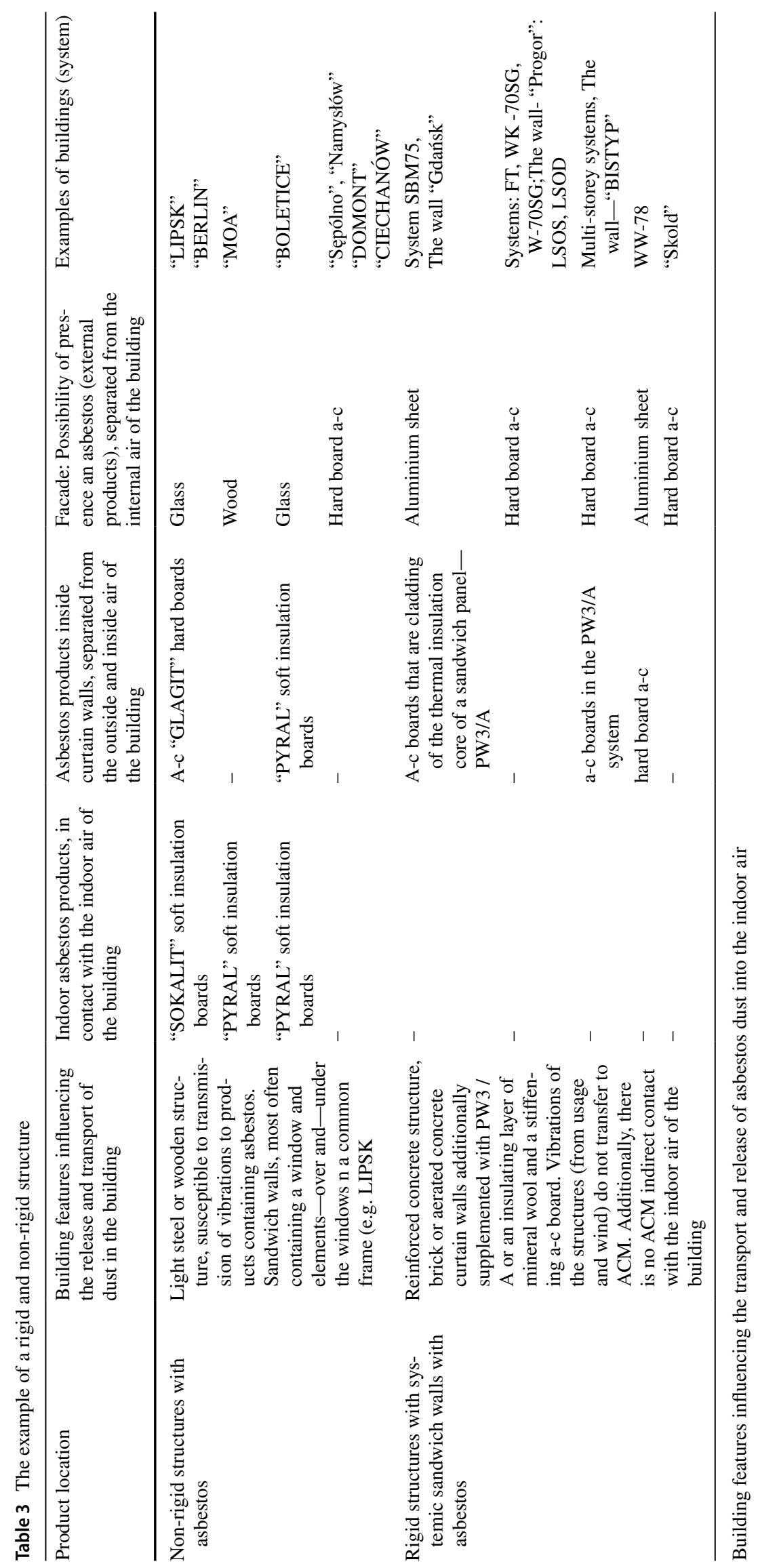


using the example of four "LIPSK" buildings. The presented objects were suitable for comparison due to the identical structure, location of asbestos-containing products, a similar way of usage, and the possibility of measurement conditions. They differed in the method of ACM operation and maintenance as well as condition of the ACM. The comparison includes 4 characteristic operating states of the buildings in use presented below in Fig. 3a, b, c1, c2, c3.

Concentration results are presented on the horizontal axis in six ranges. The vertical axis shows the percentages of these ranges. The presented series of results:

(1 and 2) Typical buildings after numerous renovations, intensively used as an office building. Renovations and modernizations damaged asbestos products, which was secured in an unprofessional manner, but reducing the temporary dustiness (red and blue curve). Buildings 1 and 2 are the most common.

(3) The building after numerous renovations and modernizations, carried out without being aware of the presence of asbestos. Unprotected damage to products in technical rooms is an active source of dust for the entire facility as a result of its normal operation (green curve).

(4) Unrenovated building in good technical condition with minimal or no damage. Pollution monitoring and ACM products condition control are carried out in the building (purple curve). The percentage shares of the groups of results for the tested four types of "LIPSK" buildings (above) and 3 years after asbestos removal from building "LIPSK" (position No 5) are presented in the Table 4.

The concentration ranges from 300 to $<500 \mathrm{f} / \mathrm{m}^{3}$ accounts for $35 \%$ of all values. Approximately $25 \%$ of the results are below the quantification limit of the method $\left(<300 \mathrm{f} / \mathrm{m}^{3}\right)$, $12 \%$ of which show the absence of asbestos fibres in the air. The frequency curve of the concentration range deviates from the symmetric Gaussian curve. This can be explained by the superimposition of the two or more, predominant pollution models in rooms (the utility rooms- "a" and the technical rooms-"b", see below in Fig. 3c1, c2, c3).

In another typical "LIPSK" with different degrees of use or damage, the dust concentration results for the entire facility may have a large scatter, even if the measurements in the individual rooms differ slightly from each other. For example, the number of measurements is 38 with an average concentration value $(\bar{a})=310 \mathrm{f} / \mathrm{m}^{3}$ with a range of measured values from 0 to $1500 \mathrm{f} / \mathrm{m}^{3}, \sigma=322$; coefficient of variation $(V)=\sigma / \bar{a} \times 100 \%=104 \%$. To confirm kind of distribution of concentration values, a separate statistical analysis of the measurements of the building No. 1 was carried out using the Shapiro-Wilk test, taking into account all the results (Fig. 3c1), the results for rooms "a" (Fig. 3c2) and rooms "b" (Fig. 3c3). Table 5 shows the values of dust concentrations in 21 rooms of this building, with a cubature of approx. 100 $\mathrm{m}^{3}$. A fan was used to mix the air with a capacity of approx. $1000 \mathrm{~m}^{3} / \mathrm{h}$ during air sampling. Two measurements were made in each of them for about $100 \mathrm{~min}$.

The Shapiro-Wilk test (in Table 6) reaches statistical significance $(p<0.05)$, which proves the distribution distant from the Gaussian curve. Conclusion: The distribution of the concentration results in each of the analysed cases is deviated from the normal distribution. Even in rooms with a similar function and operation, the rooms are separate environments and the adopted method of averaging the air ("dynamic sample") is not sufficient for its "averaging" in the dust test. The dust pollution are separate sets of values with different levels of concentration and sources. This indicates the presence of different primary and secondary sources of dust emissions in rooms cannot be attributed to a common pollution model in building.

Table 4 The percentage results of contamination in different 5 "LIPSK" buildings

\begin{tabular}{|c|c|c|c|c|c|c|c|c|c|c|}
\hline \multirow[t]{2}{*}{ Concentration range $\left[\mathrm{f} / \mathrm{m}^{3}\right]$} & \multicolumn{2}{|l|}{1} & \multicolumn{2}{|l|}{2} & \multicolumn{2}{|l|}{3} & \multicolumn{2}{|l|}{4} & \multicolumn{2}{|l|}{5} \\
\hline & A & $\mathrm{B}[\%]$ & A & $\mathrm{B}[\%]$ & A & $\mathrm{B}[\%]$ & A & $\mathrm{B}[\%]$ & A & $\mathrm{B}[\%]$ \\
\hline 0 & 6 & 15 & 2 & 10 & 0 & 0 & 66 & 41 & 7 & 27 \\
\hline$<300$ & 10 & 25 & 5 & 22 & 2 & 5 & 53 & 33 & 10 & 38 \\
\hline $300-<500$ & 13 & 32 & 9 & 39 & 3 & 11 & 22 & 14 & 6 & 23 \\
\hline $500-<700$ & 5 & 12 & 4 & 17 & 5 & 18 & 8 & 5 & 3 & 12 \\
\hline $700-<900$ & 3 & 8 & 2 & 9 & 2 & 7 & 3 & 2 & 0 & 0 \\
\hline$\geq 900$ & 3 & 8 & 1 & 4 & 15 & 55 & 8 & 5 & 0 & 0 \\
\hline Number of samples & 40 & 100 & 23 & 100 & 27 & 100 & 160 & 100 & 26 & 100 \\
\hline Average value & $<300$ & $*$ & 400 & $*$ & 1100 & $*$ & $<300$ & $*$ & $<300$ & $*$ \\
\hline Standard deviation $(\sigma)$ & 190 & & 216 & & 1600 & & $155-250$ & & 180 & \\
\hline Coefficient of variation $(V)[\%]$ & $<63$ & & 54 & & 145 & & $<52-83$ & & $<60$ & \\
\hline
\end{tabular}

"A" number of measurements; "B" percentage share

*Not applicable 
Another example of asbestos dust concentration in the one of "LIPSK" buildings after renovation is presented in Table 7. The table shows results from a building insulated

Table 5 The concentration of fibres in individual rooms of the "LIPSK" building No. 1

\begin{tabular}{|c|c|c|c|}
\hline No & Location of the sampling point & & Concentration $\left[\mathrm{f} / \mathrm{m}^{3}\right]$ \\
\hline 1 & 5 th floor, room 1 & $\mathrm{a}$ & 800 \\
\hline 2 & & & 500 \\
\hline 3 & 5th floor, technical room 1 & $\mathrm{~b}$ & 600 \\
\hline 4 & & & 900 \\
\hline 5 & 5 th floor, technical room 2 & & 1200 \\
\hline 6 & & & 1500 \\
\hline 7 & 5 th floor, room 2 & $\mathrm{a}$ & 800 \\
\hline 8 & & & 800 \\
\hline 9 & Ground floor, room 3 & & 400 \\
\hline 10 & & & 300 \\
\hline 11 & 4th floor, room 4 & & 600 \\
\hline 12 & & & No fibres \\
\hline 13 & 4th floor, room 5 & & No fibres \\
\hline 14 & & & 300 \\
\hline 15 & 4 th floor, room 6 & & $<300(200)$ \\
\hline 16 & & & $<300(200)$ \\
\hline 17 & 4th floor, technical room 3 & $\mathrm{~b}$ & 400 \\
\hline 18 & & & 400 \\
\hline 19 & 3 th floor, room 7 & $\mathrm{a}$ & 400 \\
\hline 20 & & & 400 \\
\hline 21 & 3 th floor, room 8 & & No fibres \\
\hline 22 & & & 500 \\
\hline 23 & 3 th floor, room 9 & & 300 \\
\hline 24 & & & No fibres \\
\hline 25 & 2th floor, room 10 & & $<300(200)$ \\
\hline 26 & & & $<300(200)$ \\
\hline 27 & 2th floor, room 11 & & $<300(250)$ \\
\hline 28 & & & No fibres \\
\hline 29 & First floor, room 12 & & 400 \\
\hline 30 & & & $<300(200)$ \\
\hline 31 & 4th floor, room 13 & & $<300(200)$ \\
\hline 32 & & & $<300(200)$ \\
\hline 33 & 4th floor, technical room 4 & $\mathrm{~b}$ & 400 \\
\hline 34 & & & 400 \\
\hline 35 & 3th floor, room 14 & $\mathrm{a}$ & 400 \\
\hline 36 & & & 400 \\
\hline 37 & 3 th floor, room 15 & & No fibres \\
\hline 38 & & & 500 \\
\hline 39 & 3th floor, room 16 & & 300 \\
\hline 40 & & & No fibres \\
\hline 41 & 2th floor, room 17 & & $<300(200)$ \\
\hline 42 & & & $<300(200)$ \\
\hline
\end{tabular}

"a" rooms "used", in good technical condition. "b" technical rooms with different technical condition and increased pollution with a layer of expanded polystyrene without dismantling asbestos. The study was carried approximately about one year after completion of the renovation project. The frequency of different concentration ranges takes a shape similar to a Gauss curve, although asymmetric (e.g. buildings 1 and 2) with maximum concentrations in the range of $450-750 \mathrm{f} / \mathrm{m}^{3}$. The table presents 35 measurements of concentration of asbestos dust; the range of most frequently recorded values is $300-900 \mathrm{f} / \mathrm{m}^{3}$, average $717 \mathrm{f} / \mathrm{m}^{3}$, median $750 \mathrm{f} / \mathrm{m}^{3}, \sigma=450 \mathrm{f} / \mathrm{m}^{3}$.

Four years after the end of renovation, the average concentration of asbestos fibres $<300 \mathrm{f} / \mathrm{m}^{3}$, median $<300 \mathrm{f} /$ $\mathrm{m}^{3}$. Comparison of the impact of damage on average pollution values in "LIPSK" buildings is shown in Table 8. It shows the changes in asbestos dust concentration in operated rooms of "LIPSK" type buildings with various degrees of damage to walls and ceilings from "SOKALIT". This shows currently existing differences between "LIPSK" type buildings due to their different use and degree of asbestos damage.

Concentration of asbestos respirable fibres $\left[\mathrm{f} / \mathrm{m}^{3}\right]$ in 8 types of objects in which various degrees of exploitation and damage to individual rooms were detected:

A-Buildings not renovated, in good condition;

B-Buildings a few years after renovation and adaptation works;

$\mathrm{C}$-Non-renovated rooms, adjacent to the dismantling of asbestos in one room (measurements after a few months);

Table 6 Shapiro-Wilk test for compliance of the measured dust concentration values with the normal distribution

\begin{tabular}{llcl}
\hline Results & statistics & $N$ & $\begin{array}{l}\text { Statistical } \\
\text { signifi- } \\
\text { cance }\end{array}$ \\
\hline $\begin{array}{l}\text { All from "LIPSK" } \\
\quad \text { No 1 }\end{array}$ & 0.864 & 42 & 0.000 \\
Rooms "a" & 0.908 & 34 & 0.007 \\
Rooms "b" & 0.799 & 8 & 0.028 \\
\hline
\end{tabular}

Table 7 The frequency of occurrence of different concentrations in building "LIPSK"

\begin{tabular}{llc}
\hline Series & Concentration $\left[\mathrm{f} / \mathrm{m}^{3}\right]$ & $\begin{array}{c}\text { Number } \\
\text { of result }\end{array}$ \\
\hline 1 & $<300$ & 2 \\
2 & $>300-600$ & 10 \\
3 & $>600-900$ & 11 \\
4 & $>900-1200$ & 3 \\
5 & $>1200-1500$ & 5 \\
6 & $>1500-1700$ & 2 \\
\hline
\end{tabular}


D-Rooms during the commencement of dismantling works (measurements outside the works area);

E-Rooms outside the hermetic dismantling zone, during removal of asbestos from all rooms on one floor (example of 2 buildings);

F-A few weeks after completion of dismantling;

$\mathrm{G}-6$ months after completion of dismantling, cleaning and putting into service;

$\mathrm{H}$-Five years after asbestos removal, the average concentration of respirable asbestos dust.

Similar E and G values are a consequence of dismantling errors and "leakage" that were not detected during asbestos removal.

The graph in Fig. 4 compares the differences in indoor air pollution in 6 groups of another building of the "LIPSK" system type with different conditions of ACM and intensive usage (e.g. schools, public institutions, and offices). Measurements were made using the SEM-EDS technique.

Marking was used:

- Building A, technical condition of the single rooms varied condition of ACM;

- Building B, technical condition of the rooms varied, better than in A, disassembly of partitions during operation was not carried out;

- Building $\mathbf{C}$, technical condition of rooms differed, worse than A and B, lack of well-cleaned and newly renovated rooms, intensive use;

- Buildings $\mathbf{D}, \mathbf{E}$ and $\mathbf{F}$, maintained in everyday operation in good and very good technical condition, lack of rooms in which changes in arrangement or disturbance of partition walls and curtain walls were made, rooms were kept without any visible damage.

Rooms often cleaned, without complicated equipment, easy to keep clean.

Rooms, less frequently cleaned, some rooms painted with emulsion several times, others not renewed.

Rooms in which disassembly of partition walls or computer cabling, additional modifications to the arrangement of rooms, assembly of ceiling covers from the GK board were carried out.

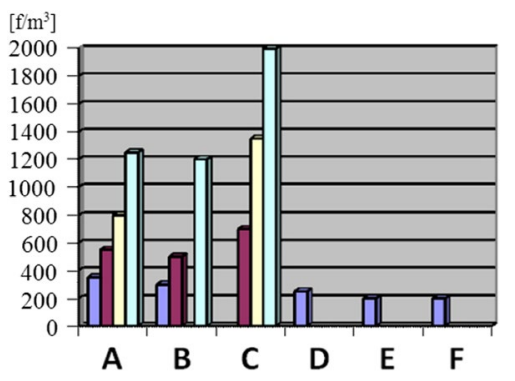

Fig. 4 The concentration of asbestos dust in various rooms of "LIPSK" type buildings with evidently different degree of damage to ACM products after 40 years of operation. Intensively used office buildings (schools, public institutions, offices)

Rooms in poor technical condition, visible damage to the curtain wall from the inside or ceiling suspended from "SOKALIT" panels.

\subsection{Average concentration of asbestos aerosol in different systems}

The averaged results of the asbestos dust concentration measurements in the rooms of tested buildings are shown in Table 9.

The red font: operational pollution of industrial facilities before asbestos removal. The values allows for comparison of pollution found in industry with that found in residential buildings. These results show that the average concentrations of asbestos dust in some building systems recorded at around $400 \mathrm{f} / \mathrm{m}^{3}$ should be considered low. Dismantling asbestos in these buildings may not improve but even worsen the cleanliness of indoor air.

Table 10 presents a comparison of tested buildings in good technical condition without any modifications or damages. In buildings of comparable size in "rigid" constructions, the dust concentration is half that in buildings of "nonrigid" constructions.

\section{Summary of discussion}

In the presented project, approximately 60 buildings were tested. About 20-60 measurements were made in each of them.

Table 8 Concentration of indoor air pollution $\left[\mathrm{f} / \mathrm{m}^{3}\right]$ in several "LIPSK" buildings during normal operation, dismantling of ACM and after complete asbestos removal

\begin{tabular}{|c|c|c|c|c|c|c|c|c|}
\hline Buildings & A & $\mathrm{B}$ & $\mathrm{C}$ & $\mathrm{D}$ & $\mathrm{E}$ & $\mathrm{F}$ & $\mathrm{G}$ & $\mathrm{H}$ \\
\hline Asbestos concentration $\left[\mathrm{f} / \mathrm{m}^{3}\right]$ & $<300-500$ & & $400-1100$ & $2000-5000$ & $<50,000$ & 5000 & $600-1000$ & $0-300$ \\
\hline
\end{tabular}




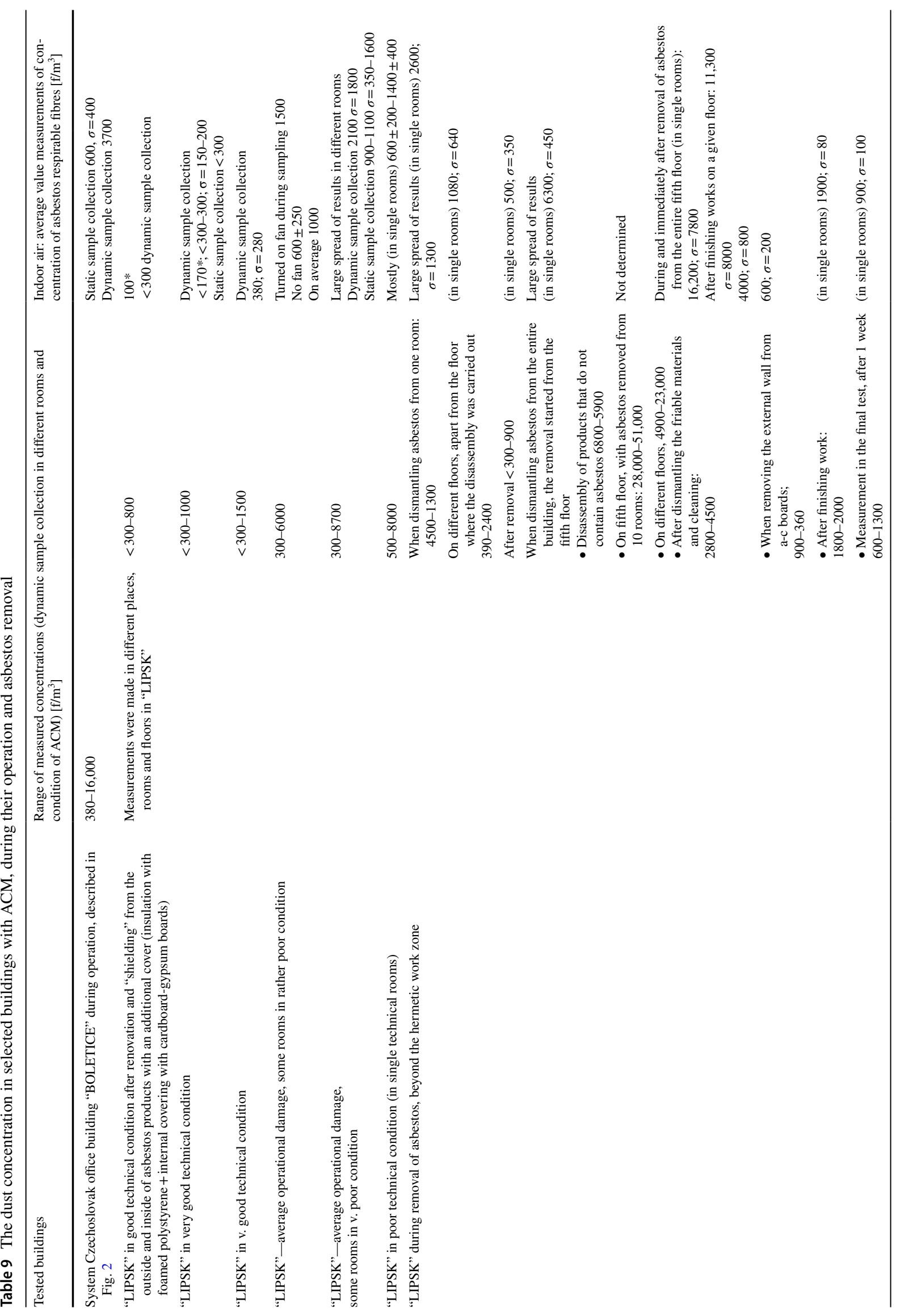




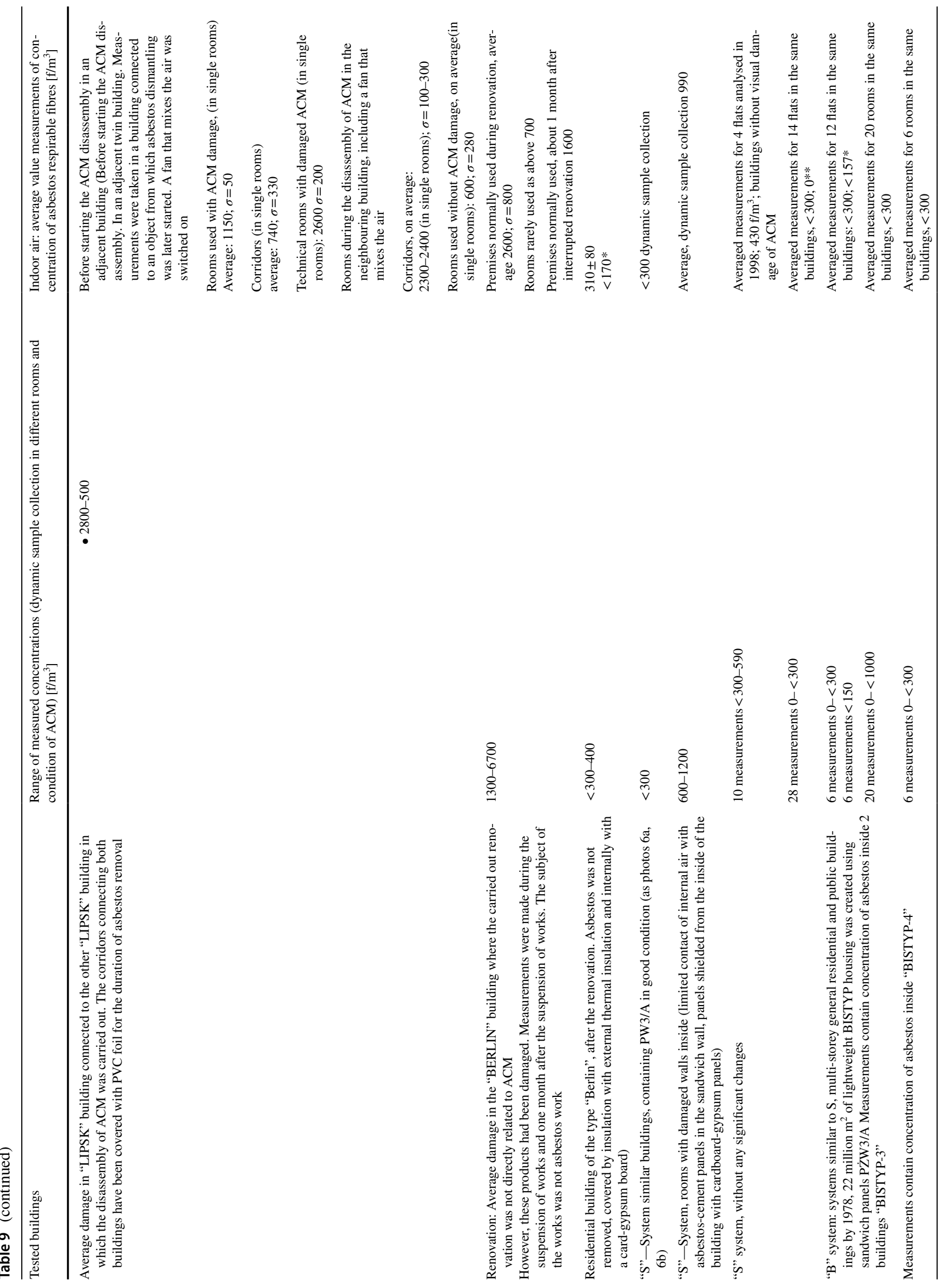


Based on the analysis of all examined buildings, a working hypothesis can be formulated regarding the variability of asbestos dust concentrations in the air. The greatest variability is related to objects that have or have had damage to asbestos products and sampled with a dynamic method (as in "LIPSK"). The standard deviation may be $>90 \%$ of the arithmetic mean value of the results. In case good condition o ACM I buildings, it can be $\approx 50-60 \%$. When sampling using the static method, the air is less diverse and depended on the ACM condition in individual rooms. The standard deviation for the contamination values may be small. The lowest variability of the results is in the objects with moderately and low concentrations in samples collected from single rooms. These are found in buildings with good technical condition.

Case I. Slight differences in indoor dust concentration values were measured in different room of the same building, when:

- there are no damaged ACM products in the facility with dust that can turn into an aerosol and when the circumstance of aerosol formation is limited (no vibrations of ACM structures and products, strong air movements);

- in some cases, in the single rooms during the process of disassembly or assembly of the ACM products. The rooms were closed and measurements were taken directly after destruction of ACM and intensive air mixing was started during the research, thus ensuring even distribution of unbound dust in the tested cubature;

- measurements were carried out in rooms during normal use, with low asbestos dust levels $\left(<500 \mathrm{f} / \mathrm{m}^{3}\right)$;

- in rooms/buildings operated without destruction of ACM products for a long period of use (from a couple of years to several decades) and the value of pollution found was low $\left(<400 \mathrm{f} / \mathrm{m}^{3}\right)$;

- in rooms and buildings currently out of using or properly use without asbestos damage $\left(<300-400 \mathrm{f} / \mathrm{m}^{3}\right)$.

Case II. Large differences between the dust concentration values in a single room or in different rooms in the same building were measured when:

- a longer time elapsed between the ACM destruction and the dust concentration measurements (part of the dust is deposited by gravity and under normal conditions of air sampling, it does not become aerosol);

- buildings or rooms used after completion of renovations or improperly conducted dismantling, e.g. after a period of a few to several months from the completion of such works. The tested rooms differed in the intensity of use;

- in rooms where there were active sources of asbestos dust release (damaged ACM products subject to vibration during collecting air samples) and there was air movement or 
Table 10 Average ranges of values of operational pollution in various types of buildings in good condition—recorded by OM

\begin{tabular}{|c|c|c|c|c|c|}
\hline Building system & Production place & Building structure & $\begin{array}{l}\text { Product used } \\
\mathrm{Z} \text { - externally } \\
\mathrm{W} \text {-internally ACM in } \\
\text { a sandwich wall }\end{array}$ & $\begin{array}{l}\text { Estimated quantity } \\
\text { of product [ } \mathrm{t}]\end{array}$ & $\begin{array}{l}\text { Average ranges of values in } \\
\text { operational pollution }\left[\mathrm{f} / \mathrm{m}^{3}\right]\end{array}$ \\
\hline "BOLETICE" & CSRS & \multirow[t]{3}{*}{ Non-rigid, steel } & $\mathrm{W}$ & 250 & $600-700$ \\
\hline "LIPSK" & GDR (DDR) & & $\mathrm{Z}+\mathrm{W}$ & 140 & $300-700$ \\
\hline "BERLIN" & $\begin{array}{l}\text { GDR } \\
\text { (DDR) }\end{array}$ & & $\mathrm{Z}+\mathrm{W}$ & $15-20$ & $<300-500$ \\
\hline "Ciechanów C-40" & Poland & \multirow[t]{2}{*}{ Non-rigid, wooden } & $\mathrm{Z}$ & 15 & $300-500$ \\
\hline "DOMONT" & Poland & & $\mathrm{Z}$ & 15 & $300-600$ \\
\hline "OWT" & Poland & \multirow{3}{*}{$\begin{array}{l}\text { Rigid (brick or rein- } \\
\text { forced concrete) }\end{array}$} & $\mathrm{Z}$ & $25-35$ & $<300-500$ \\
\hline "WW-78" & Poland & & $\mathrm{PW} / 3 \mathrm{~A}$ & 100 & $<300$ \\
\hline "BISTYP" 3 and 4 & Poland & & $\mathrm{PW} / 3 \mathrm{~A}$ & 100 & $<300$ \\
\hline
\end{tabular}

Fig. 5 An approximate calculator for asbestos pollutant estimation in buildings. The range of average concentration values for the entire building

. The range of concentration values in the rooms of the tested building

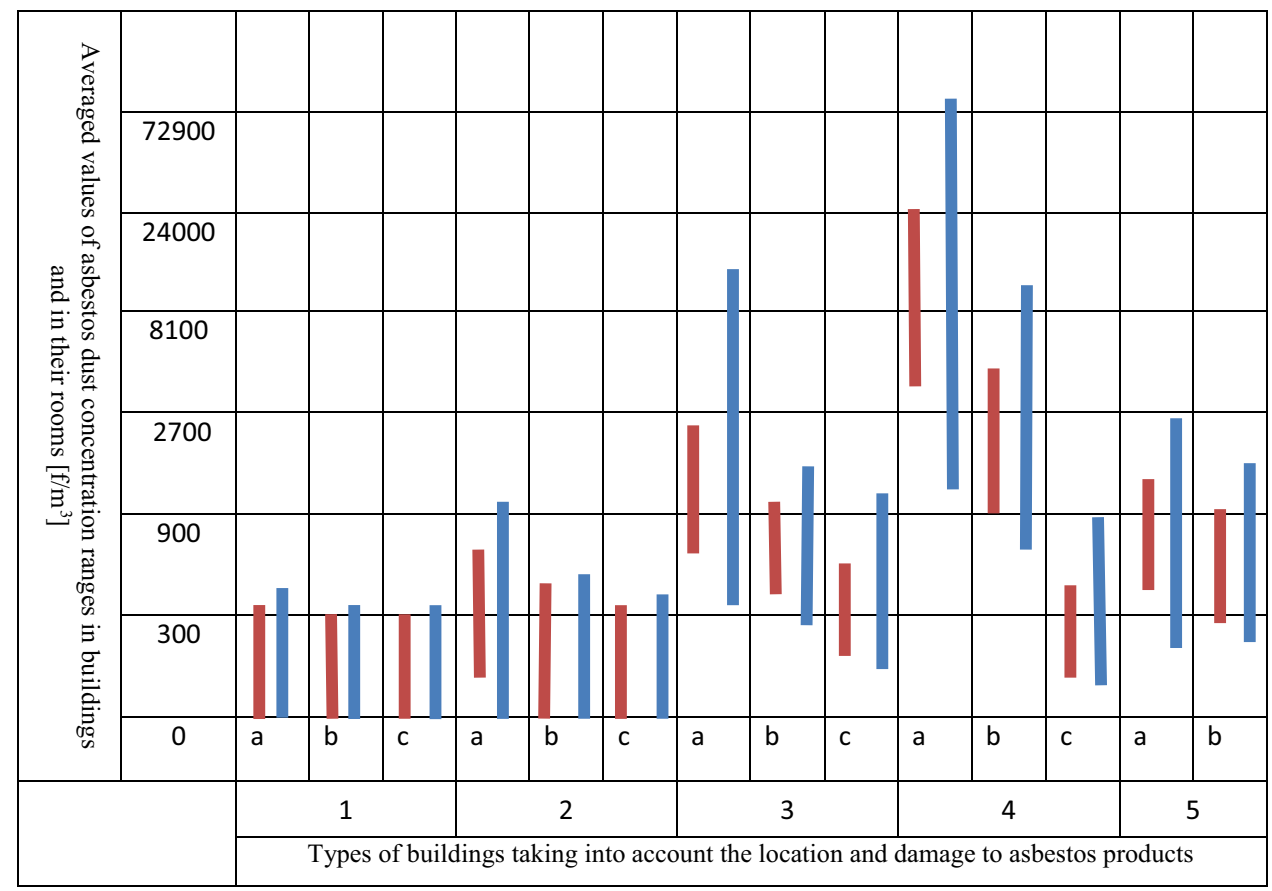

an active form of room operation and the rooms differed in the amount or scale of damage ACM.

A summary of the approximate values of asbestos dust concentrations in three common types of general construction buildings is shown in Fig. 5 .

Marking was used:

(1) Normal use, standard product protection, no visible damage.

(2) Normal use, minor damage to asbestos-containing products, up to approx. $1 \%$ of the surface of asbestoscontaining products.

(3) Visible damage in neglected buildings where about $10 \%$ or more of the surface of asbestos-containing products is damaged, mechanical and structural damage caused by wall freezing, water penetration with missing or damaged protective coatings. Also buildings in which the disassembly of installation products has begun, constituting an introduction to asbestos disassembly.

(4) Facilities during asbestos removal (space outside the direct hermetic zone of disassembling work).

The max value applies to the period of works, the minimum value applies to the term one week after completion of works.

(5) Facilities after asbestos dismantling, up to one month after completion of works:

(a) Buildings of the "LIPSK", "BERLIN" type; containing "SOKALIT" soft boards inside and hard 
a-c boards outside the building (under a glass or sheet facade;

(b) Reinforced concrete buildings with "BISTYP" sandwich walls or wooden buildings with PW3/A panels, without the panels in direct contact with internal air;

(c) Brick buildings with a-c panel facade.

Additional contamination level corrections depending on individual factors and operating conditions (referring to structures transmitting vibrations to asbestos products in buildings):

In Fig. 5 maximum modifications for the values of columns 1,2 , and 3 each time, when:

- intensive use (e.g. schools, kindergartens, sports halls), additional "friable" installations, products in ventilation systems - to add $300-500 \mathrm{f} / \mathrm{m}^{3}$;

- no operation, tightly covering the products with an impregnating coating or tight gypsum board construction, frequent ventilation- to subtract $200-300 \mathrm{f} / \mathrm{m}^{3}$.

One of the most important factors influencing the amount of contamination (increase) of asbestos concentration in the surroundings of the building and its interior is the treatment processes of ACM products occurring during their assembly (in the past). Currently, they are the way and intensity of exploitation and disassembly of products using inappropriate techniques and tools. This is confirmed, inter alia, by report [40], with the geometric mean in such processes of $7000 \mathrm{f} / \mathrm{m}^{3}$ and $\sigma=5000 \mathrm{f} / \mathrm{m}^{3}$ (concentration range 1000-340,000 f/ $\mathrm{m}^{3}$ ).

\section{Conclusions}

(1) In buildings containing ACM inside sandwich walls in good technical condition, dust concentrations were at the level of $<300-400 \mathrm{f} / \mathrm{m}^{3}$. The differences between rooms in the building were small. In buildings with a "rigid structure", when ACM products are not in direct contact with internal air, normal operation will not increase air pollution by asbestos dust. Therefore, in these kinds of facilities it can be assumed that, with proper building usage and confirmation of low indoor asbestos fibres concentration, this concentration will tend to equal the outdoor level over time.

(2) The differentiation in the dust concentration values in the tested building depends on the scale of damage to the products, the degree of air averaging in the building, the method of sampling and many other factors, which are often difficult to register or predict.
(3) In buildings with asbestos-containing interior products, where there are differences in the type of damage, the distribution of dust concentrations differs from the normal distribution presented by the Gauss curve. The whole building cannot be treated as a room with homogeneous pollution.

(4) The coefficient of variation of the results may exceed $100 \%$ of the average value and for the air characteristics of such buildings, rooms significantly different from the average should be treated separately.

(5) The values of highly dispersed dust aerosols, e.g. found in buildings in use or in the surrounding air (as opposed to very high concentrations, e.g. during asbestos removal area) should be treated as approximate values, changing significantly in a place and over the time. The results require multiple air samples from different rooms and averaging the pollutants in the air by mixing them over a long period of time.

(6) During the tests, it is required to take into account other factors influencing the dust concentration in the indoor air.

\subsection{Suggestion of further research}

The extensive bibliography and the presented studies provide qualitative descriptions of concentrations. There are no quantitative descriptions showing, for example, the relationship between the surface of ACM products, quantitative damage, cubature, scale of use, and the level of dust concentration. Such quantitative research would allow the estimation of the concentration values of the former based on the description of the building without performing the research. An attempt at such quantitative estimates is to identify trends in pollution changes in specific types of buildings. It is also advisable to determine the variation in an actual concentration values taking into account the time elapsed between the building or damage and the test of indoor air contamination.

Author contributions All contributor roles were made by one person, who was the author andcorresponding author, including: (conceptualization, data curation, formal analysis, fundingacquisition, investigation, methodology, project administration, resources, software,supervision, validation, visualization, writing —original draft, writing-review and editing).

Funding No funding.

Data availability Author declared that all data and materials as well as software application support hispublished claims and comply with field standards. 


\section{Declarations}

Conflict of interest Author declares that he has no conflict interest.

Research involving human participants and/or animals This article does not contain any studies with human participants or animals performed by the author.

Informed consent Not applicable.

Open Access This article is licensed under a Creative Commons Attribution 4.0 International License, which permits use, sharing, adaptation, distribution and reproduction in any medium or format, as long as you give appropriate credit to the original author(s) and the source, provide a link to the Creative Commons licence, and indicate if changes were made. The images or other third party material in this article are included in the article's Creative Commons licence, unless indicated otherwise in a credit line to the material. If material is not included in the article's Creative Commons licence and your intended use is not permitted by statutory regulation or exceeds the permitted use, you will need to obtain permission directly from the copyright holder. To view a copy of this licence, visit http://creativecommons.org/licenses/by/4.0/.

\section{References}

1. Upton AC. Asbestos in public and commercial buildings-A literature revive and synthesis of current knowledge. Health Effect Institute, Asbestos Research. Cambridge; 1991.

2. Gaualtieri AF, Mangano D, Gualtieri ML, Richi A, et al. Ambient monitoring of asbestos in selected Italian living areas. J Environ Manage. 2009. https://doi.org/10.1016/j.jenvman.2009.06.007.

3. SRC. Inc Denver. CO Summary of Published Measurements of Asbestos Levels In Ambient Air Prepared for USA EPA Region 8. Denver 05/20/2013

4. Szeszenia-Dąbrowska N, Sobala W. Environmental pollution of asbestos health effects research report. Łódź; 2008 (in Polish).

5. A literature revive of Australia and overseas studies on The air borne asbestos fibres from building materials as result of weathering and/or corrosion, Australian Government, Australian Safety and compensation, Counsil Commontweath of Australia. http:// www.ag.gov.au/cca (2008)

6. Burdett GJ, Dewberry K, Staff J. Airborne asbestos exposures from warm air heating systems in schools. Ann Occup Hyg. 2016. https://doi.org/10.1093/annhyg/mev062.

7. Burdett GJ, Delphine B. Exposure of UK industrial plumbers to asbestos Part I Monitoring of exposure using personal passive samplers. Ann Occup Hyg. 2007. https://doi.org/10.1093/annhyg/ mel078.

8. Fathabadi MK, Abdolahnejad A. Spatio-seasonal variation of airborne asbestos concentration in urban areas of Shiraz. Iran Int J Occup Environ Health. 2018. https://doi.org/10.1080/10773525. 2018.1436016.

9. Lotter JT, Roberts B, Henshaw JL. Airborne asbestos exposure associated with the installation and removal of roofing products. J Occup Environ Hyg. 2016. https://doi.org/10.1080/15459624. 2016.1183010 (withdrawn article).

10. Brown SK. Asbestos exposure during renovation and demolition of asbestos-cement clad buildings. Am Ind Hyg Assoc J. 1987. https://doi.org/10.1080/15298668791385075.

11. Mowat F, Weidling R, Seehan P. Simulation test to assess occupational exposure to airborne asbestos from asphalt—based roofing products. Ann Occup Hyg. 2007. https://doi.org/10.1093/annhyg/ mem020

12. Lange JH, Lange PR, Reinhard TK, Thomulka KW. Area and personal airborne exposure during abatement of asbestos-containing roofing material. Bull Environ Contam Toxicol. 2000. https://doi. org/10.1016/0003-4878(95)00081-x.

13. Crump KS, Farrar DB. Statistical analysis of data on airborne asbestos levels collected in an EPA survey of public buildings. Regul Toxicol Pharmacol. 1989. https://doi.org/10.1016/02732300(89)90012-3.

14. Lee RJ, Van Orden DR, Corn M, Crump KS. Exposure to airborne asbestos in buildings. Regul Toxicol Pharmacol. 1992. https://doi. org/10.1016/0273-2300(92)90024-4.

15. Kim YC, Hong WH, Zhang YL. Development of a model to calculate asbestos fiber from damaged asbestos slates depending on the degree of damage. J Clean Prod. 2015. https://doi.org/10.1016/j. jclepro.2014.08.092.

16. Corn M, Crump K, Farrar DB, Lee RJ. Airborne concentrations of asbestos in 71 school buildings. Regul Toxicol Pharmacol. 1991. https://doi.org/10.1016/0273-2300(91)90044-V.

17. Young J, Kelly M, Vance L. Determination of size fractions and concentrations of airborne particulate matter generated from construction and demolition waste processing facilities. Air Qual Atmos Health. 2008. https://doi.org/10.1007/s11869-008-0015-x.

18. Besson P, Lalanne FX, Wang Y. Multi-parameter observation of environmental asbestos pollution at the Institut de Physique du Globe de Paris (Jussieu Campus, France). Ann Occup Hyg. 1999. https://doi.org/10.1016/S0003-4878(99)00041-1.

19. Database "EVALUTIL", http://etudes.insped.w-bordeaux 2 .freva lutil Base de données Ev@ @util - Santé publique France http:// etudes.isped.u-bordeaux2.fr/evalutil003/

20. Abelmann A, Maskrey JR, Lotter JT. Evaluation of take-home exposure to asbestos from handling asbestos-contaminated worker clothing following the abrasive sawing of cement pipe. Inhal Toxicol. 2017. https://doi.org/10.1080/08958378.2017.1418940.

21. Latif MT, Baharudin NH, Velayutham P, et al. Composition of heavy metals and airborne fibres in the indoor environment of a building during renovation. Environ Monit Assess. 2011. https:// doi.org/10.1007/s10661-010-1843-3.

22. Szeszenia-Dąbrowska N, Świątkowska B. Asbestos in Poland, Environmental pollution, health effects, principles of safe asbestos handling. Łódź; 2016 (in Polish).

23. Obmiński A. Problems of the pollution of buildings using asbestos-containing products. IV Poland-wide interdisciplinary scientific and technical conference "Ecology and construction" Bielsko-Biała; 1992 (in Polish).

24. Obmiński A. Air pollution with asbestos dust during works to dismantle asbestos-containing products. Conference Silesian Building Forum. Katowice; 2015 (in Polish).

25. Obmiński A. Technical problems of asbestos removal from buildings "LIPSK". In: Runkiewicz L, editor. Ecology and construction. Wrocław; 2016 (in Polish)

26. Obmiński A. Assessment of the condition of the safe use of asbestos-containing products. Guidelines, Tutorials ITB, Warszawa; 2014 (in Polish)

27. Obmiński A. Asbestos in buildings. Scientific Studies ITB, Warsaw; 2017 (in Polish)

28. Dyczek J. Conference "Asbestos Risk reduction \& measurement of asbestos fibre concentration", AGH University of Science and Technology Faculty of Materials Science and Ceramics Department of Building Materials, September 28-29, Cracow; 2006 (in Polish)

29. Reynolds SJ, Kreiger RA, Bohn JA, et al. Factors affecting airborne concentrations of asbestos in commercial building. J Occup Environ Hyg. 1994. https://doi.org/10.1080/15428119491018547. 
30. Sahmel J, Avens H, Scott PK, et al. Measured removal rates of chrysotile asbestos fibers from air and comparison with theoretical estimates based on gravitational settling and dilution ventilation. Inhal Toxicol. 2015. https://doi.org/10.3109/08958378.2015. 1110216.

31. Lange JH, Lange PR, Thomulka KW, Reinhard TK. A study of personal and area airborne asbestos concentrations during asbestos abatement: a statistical evaluation of fibre concentration data. Ann Occup Hyg. 1996. https://doi.org/10.1016/0003-4878(95) 00081-X.

32. Donovan EP, et al. Evaluation of bystander exposures to asbestos in occupational settings: a review of the literature and application of simple. Crit Rev Toxicol. 2011. https://doi.org/10.3109/10408 444.2010.506639.

33. Standard PN EN ISO 16 000-7 Part 7: Sampling strategy for determining the concentration of asbestos fibres contained in air

34. VDI 32492 Indoor air measurement - Ambient air measurement - Measurement of inorganic fibrous particles - Scanning electron microscopy method 2013 BGI/GUV-1 505-46. 2014-02. MSA 2.1/. UBO REM BG-. GUV-1505.46. Method for the separate determination of respirable asbestos fibres and other inorganic. Deutsche Akkreditierungsstelle GmbH Annex to the Accreditation Certificate D-PL- 11035-01-00 according to DIN EN ISO/ IEC 17025:2015

35. Air quality-Determination of the asbestos fibre concentration by transmission electron microscopy - Indirect method Edition December 2020 - Qualité de l'air - Détermination de la concentration/ dosage en fibres d'amiante par microscopie électronique à transmission - Méthode indirecte Questions - Réponses
Métrologie Amiante Direction Générale du Travail Remise à jour 2020; Annexe 3 guide GA X 46-033 d'application de la norme NF EN ISO 16000-7 Stratégie d'échantillonnage pour la détermination des concentrations en fibres d'amiante en suspension dans l'air. Août 2012

36. NIOSH 7400 (OSHA) Asbestos and other fibers by PCM: Method 7400, 1994

37. Kropiunik H. Asbestos air monitoring correlation between results of PCM and SEM measurements. Asbestos Risk reduction \& measurement of asbestos fibre concentration. In: Dyczek J, editor. Conference Cracow. 2 Sep 2006

38. Chesson J, Rench JD, Schultz BD, Milne KL. Interpretation of airborne asbestos measurements. Risk Anal. 1990. https://doi.org/ 10.1111/j.1539-6924.1990.tb00527.x.

39. PN-88/Z-04202/02 Polish standard Air purity protection. Asbestos content testing. Optical microscopy method to determine the numerical concentration of respirable asbestos fibres at workplaces 2002

40. Kim JY, Lee SK, Lee JH, Lim MH, Kang SW, Phee YG. A study on the factors affecting asbestos exposure level from asbestos abatement in building. J Korean Soc Occup Environ Hyg 2009;815, Quarterly/2384-132X(pISSN)/2289-0564(eISSN)

Publisher's Note Springer Nature remains neutral with regard to jurisdictional claims in published maps and institutional affiliations. 